\title{
Color Characteristics of Blue to Yellow Beryl from Multiple Origins
}

Yang Hu and Ren Lu

Aquamarine and heliodor are colored by Fe ions, an important coloring agent for beryl. Blue to yellow gem beryl was studied by quantitative spectroscopy and trace-element analytical techniques to explore color characteristics and chromophores. Blue color was caused by a $600 \mathrm{~nm}$ absorption, while yellow color was attributed to an absorption edge in the violet-blue region. Color ranged from blue to green to yellow due to different proportions of Fe ions with various valences and occupancies. Mn content was positively related to Fe, but abundant Mn ions showed no impact on color (unlike $\mathrm{Mn}$ in morganite and red beryl). The arrangement of alkali ions and water in channel and the charge compensation mechanism of beryl are discussed. Alkali ions (mainly Na and Cs) and water were localized in the peanut-shaped channels, and all alkali elements ( $\mathrm{Li}, \mathrm{Na}, \mathrm{K}$, $\mathrm{Rb}$, and $\mathrm{Cs}$ ) were relevant. Though alkali ions and water interacted with transition metal Fe and $\mathrm{Mn}$ ions, their influence on blue to yellow color was indirect and rather weak.


em beryl is a significant gem species, including color varieties such as emerald, aquamarine, heliodor, goshenite, morganite, and red beryl. Blue to yellow beryl has been found in numerous locations, including Brazil, South Africa, Russia, Ukraine, Canada, Myanmar, the United States, Afghanistan, and China (Belakovskiy et al., 2005).

Blue color in aquamarine and yellow color in heliodor are attributed to abundant Fe ions (Wood and Nassau, 1968). Fe ions are also present in all other color varieties of beryl, though Fe content is relatively low in morganite. Although discussions on the role of Fe ions in blue to yellow beryl are not new, they have mainly focused on crystal physics and chemistry. This article explores the color characteristics and chromophore ions of blue to yellow beryl using quantitative chemical and spectral analysis.

The crystal structure of beryl is unique for having a peanut-shaped "channel" along the c-axis, and alkali ions in this channel interact with transition metal ions. Therefore, we will discuss the features of alkali elements and their roles in beryl color, based on analysis of the channel mechanism. This research was part of a series of ongoing studies on the color characteristics of beryl.

See end of article for About the Authors and Acknowledgments.

Gems \& Gemology, Vol. 56, No. 1, pp. 54-65,

http://dx.doi.org/10.5741/GEMS.56.1.54

(C) 2020 Gemological Institute of America

\section{MATERIALS AND METHODS}

Beryls from different origins were gathered and 14 of them with various color and alkali content were selected for this study (see table 1). They were classified in the following color varieties: goshenite (colorless to near-colorless), aquamarine (greenish blue to blue), green beryl (green to yellowish green), and heliodor (greenish yellow to yellow). With the exception of two faceted stones and one rough stone, the samples were

\section{In Brief}

- Color in beryl ranges from blue to green to yellow due to different proportions of Fe-related absorption.

- The color of green beryl can also come from $\mathrm{Cr}^{3+}$ and/or $\mathrm{V}^{3+}$ ions.

- Alkali elements and water in beryl were found to play complex roles, but their influence on blue to yellow color is indirect and likely weak.

fabricated as optical wafers perpendicular (PK-7 and PK-8) or parallel (PK-5, PK-10, PK-9, RUS-8, MOZ-2, BM-1, MOZ-1, AF-3, and AF-2) to the c-axis (figure 1).

All samples were investigated by standard gemological testing, Raman spectroscopy, Fourier-transform near-infrared (FT-NIR) and ultraviolet/visible/ near-infrared (UV-Vis-NIR) spectroscopy, and laser ablation-inductively coupled plasma-mass spectrome- 


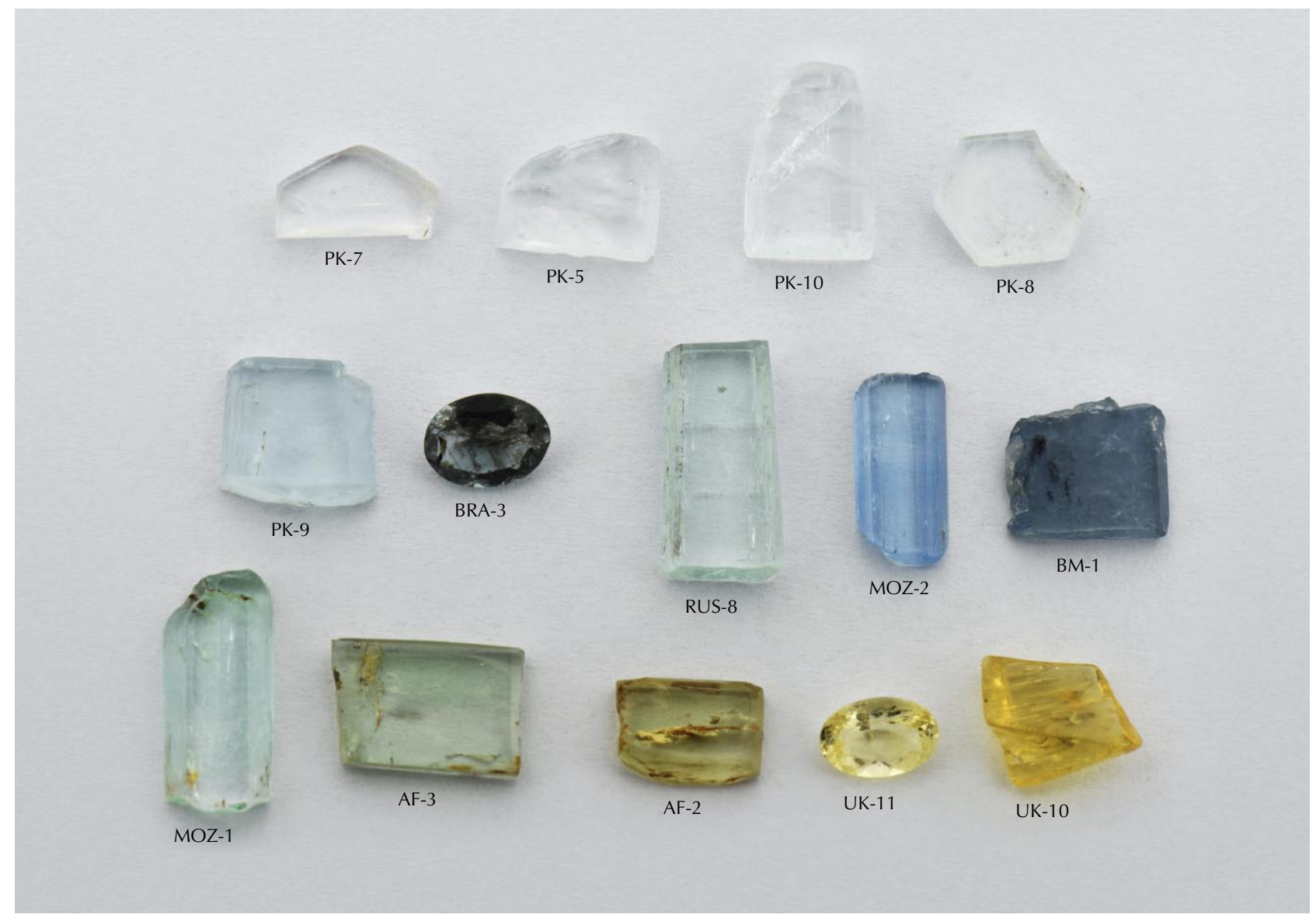

Figure 1. The 14 studied beryl samples $(0.63-3.50 \mathrm{ct}$ ) from various geographic origins. Color ranged from blue to yellow, as well as near-colorless and colorless. Photo by Yang Hu.

try (LA-ICP-MS) chemical analyses. Inclusions were captured using a Leica M205A microscopic system with oblique fiber-optic illumination. Raman spectra were collected by a Bruker Senterra R200 spectrometer coupled with a $532 \mathrm{~nm}$ laser for identifying various inclusions. The resolution was set at $5 \mathrm{~cm}^{-1}$ with a 20 second integration time, 2 accumulations, and $20 \mathrm{mV}$ laser energy. To explore the characteristics of water in the beryl, FT-NIR was performed using a Bruker V80 FTIR spectrometer at $2 \mathrm{~cm}^{-1}$ resolution and 32 accumulations. To study the color features, UV-Vis-NIR spectra were recorded with a PerkinElmer 650s spectrophotometer equipped with a $150 \mathrm{~nm}$ integrating sphere accessory at $1 \mathrm{~nm}$ resolution.

Chemical analysis was performed by LA-ICP-MS using an Agilent 7500a and 7900 ICP-MS instrument combined with a GeoLas $193 \mathrm{~nm}$ laser. The carrier gas used in the laser ablation unit was He with a flow rate set at approximately $650 \mathrm{~mL} / \mathrm{min}$. Laser ablation conditions consisted of a $44 \mu \mathrm{m}$ diameter laser spot size, a fluence of $5-6 \mathrm{~J} / \mathrm{cm}^{2}$, and a $6-8 \mathrm{~Hz}$ repetition rate. Each analysis incorporated a background acquisition time of approximately 20-30 seconds followed by 50 seconds of ablation. A multi-standard quantitative calculation method was adopted, with Al chosen as the normalizing element. Calibration standards of NIST 610, BCR-2G, BHVO-2G, and BIR$1 \mathrm{G}$ were used as external references (Liu et al., 2008). Three laser spots for each sample were applied in an area that was typically clean with an even color distribution. UV-Vis-NIR spectra were collected in the same area analyzed by LA-ICP-MS.

\section{RESULTS}

Gemological Properties. The beryl samples had a refractive index range of $\mathrm{n}_{\mathrm{e}}=1.568-1.579$ and $\mathrm{n}_{\mathrm{o}}=1.573-1.586$, with birefringence between 0.005 and 0.006 , with the exception of samples BM-1 and BRA3. Pale green MOZ-1 had the lowest RI (1.568-1.573) among all the samples. Burmese deep blue sample BM-1 and Brazilian dark greenish blue BRA-3 had the highest RI (1.589-1.600) and birefringence (0.009- 

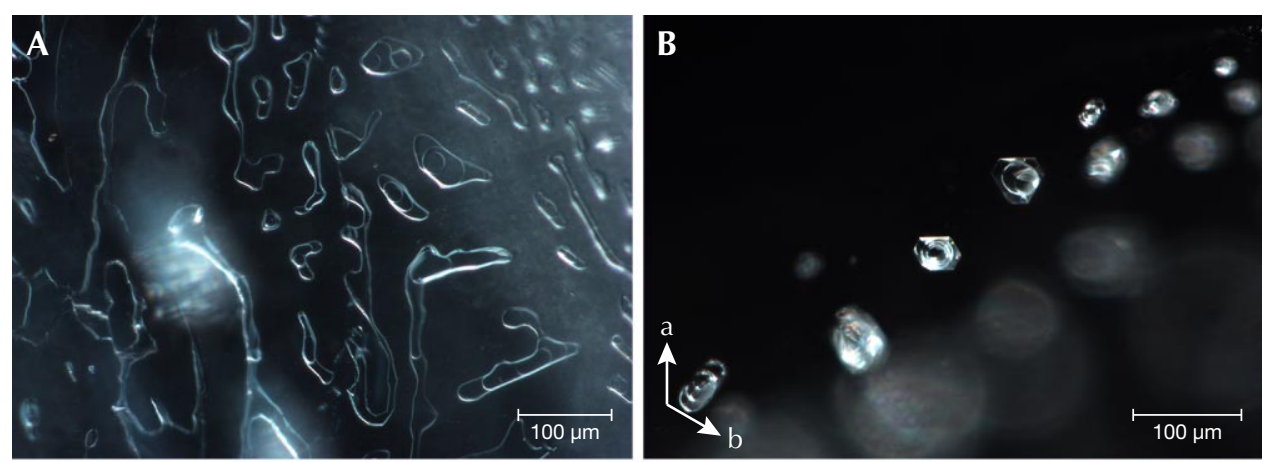

Figure 2. Two-phase inclusions in blue to yellow beryl samples. A: Fingerprint-like twophase inclusions along a healed fissure plane in aquamarine. $B$ : Hexagonal two-phase inclusions viewed
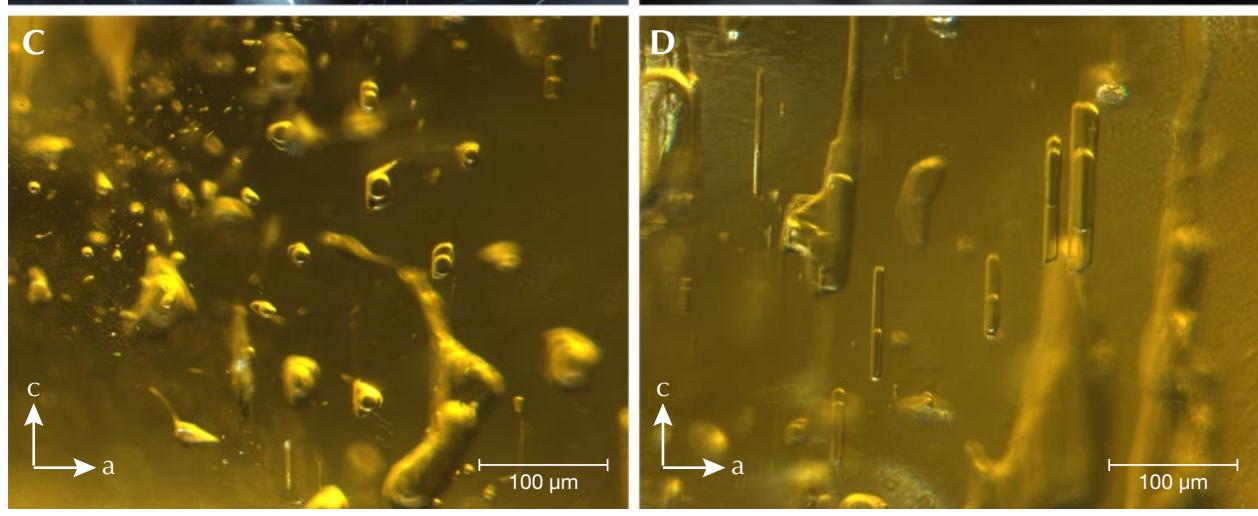
down the c-axis in aquamarine, consistent with the crystallographic symmetry. C and D: Isolated elongated rod-like twophase inclusions parallel to the c-axis in heliodor. Photomicrographs by Yang Hu.

0.010). All the beryl samples displayed weak to moderate dichroism. All bluish beryl samples showed more blue color along the e-ray than the o-ray. It should be noted that the dark hue of sample BRA-3 was caused by extremely tiny cloudy dark inclusions throughout nearly the whole sample. The lemon and yellow heliodor samples showed weak dichroism but a relatively saturated color.
Microscopic Observation. Two-phase inclusions were the most common type in the beryl samples, containing one gas bubble $\left(\mathrm{CO}_{2}\right)$ floating in at least one kind of fluid (figure 2). Minor $\mathrm{CH}_{4}, \mathrm{H}_{2} \mathrm{~S}$, and $\mathrm{N}_{2}$ were found only in some of the Pakistani beryl samples. Normally the Pakistani samples had two liquid phases $\left(\mathrm{CO}_{2}\right.$ and water with minor dissolved $\mathrm{CO}_{2}$ ), while samples from other deposits hosted one liquid phase (water). Some-

TABLE 1. Blue to yellow beryl samples selected for this study.

\begin{tabular}{llll}
\hline Sample no. & Variety & Geographic origin & Color \\
\hline PK-7 & Goshenite & Shigar Valley, Pakistan & Near-colorless \\
PK-5 & Goshenite & Shigar Valley, Pakistan & Near-colorless \\
PK-10 & Goshenite & Shigar Valley, Pakistan & Colorless \\
PK-8 & Aquamarine & Shigar Valley, Pakistan & Near-colorless \\
PK-9 & Aquamarine & Shigar Valley, Pakistan & Pale greenish blue \\
BRA-3 & Aquamarine & Brazil & Dark greenish blue \\
RUS-8 & Aquamarine & Russia & Greenish blue \\
MOZ-2 & Aquamarine & Mozambique & Blue \\
BM-1 & Aquamarine & Mogok, Myanmar & Deep blue \\
MOZ-1 & Green beryl & Mozambique & Pale green \\
AF-3 & Green beryl & Africa & Yellowish green \\
AF-2 & Heliodor & Africa & Greenish yellow \\
UK-11 & Heliodor & Unknown & Lemon yellow \\
UK-10 & Heliodor & Unknown & Golden \\
\hline
\end{tabular}




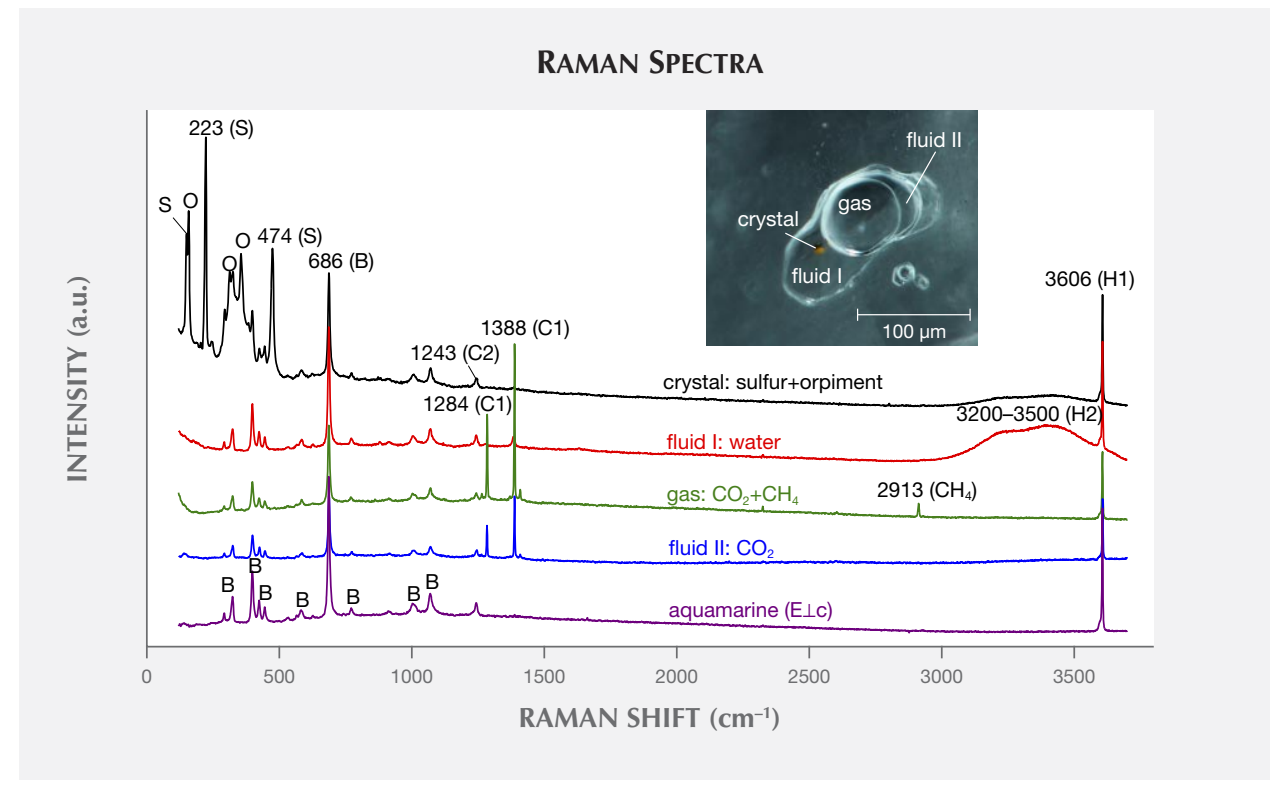

Figure 3. This multiphase inclusion had two fluid phases, one gaseous phase, and one crystal phase. Abbreviations: $B$-beryl, $S$ sulfur, $\mathrm{O}$-orpiment, $\mathrm{C1}-\mathrm{CO}_{2}$ in the inclusion, $\mathrm{C} 2-\mathrm{CO}_{2}$ in the beryl structure channel, H1-water in the beryl structure channel, and H2-water in the inclusion. Spectra are offset vertically for clarity. Photomicrograph by Yang Hu.

times a mineral phase was hosted in the fluid, such as native sulfur and orpiment in Pakistani samples (see figure 3). Two-phase inclusions had hexagonal, elongated, round, oval, angular, needle-like, or other irregular shapes. They were generally distributed along healed fissure planes forming "fingerprint-like" inclusions or isolated (again, see figure 2).

Our heating experiments indicated that two-phase inclusions transformed after heat treatment at $400^{\circ} \mathrm{C}$ or higher. Before heat treatment, a round bubble was floating on the fluid phase (figure 4, left). While cooling the sample to room temperature after heating to $300^{\circ}$ and $400^{\circ} \mathrm{C}$, we photographed the same two-phase inclusion (figure 4, middle and right). The round bubble disappeared after heating above $400^{\circ} \mathrm{C}$. Raman analysis of this two-phase inclusion detected no gas or fluid. We concluded that micro-cracks occurred after heating above $400^{\circ} \mathrm{C}$, allowing the gaseous and fluid phase to escape and leaving the empty two-phase inclusion (recognizable by its original shape and distribution). Yellowish and greenish beryl are usually heated between $400^{\circ}$ and $500^{\circ} \mathrm{C}$ to obtain a blue color, so this empty two-phase inclusion could potentially be used as evidence of heat treatment of aquamarine.

Various mineral inclusions could be detected by Raman spectroscopy. Tourmaline, albite, muscovite, garnet, zircon, and tantalite-columbite were typical in our samples (figure 5). Argentojarosite was identi-

Figure 4. A two-phase inclusion before and after heat treatment at $300^{\circ}$ and $400^{\circ} \mathrm{C}$. The gaseous and fluid phases disappeared after heat treatment above $400^{\circ} \mathrm{C}$. Left: Unheated. Center: After heating to $300^{\circ} \mathrm{C}$ and cooling to room temperature. Right: After heating to $400^{\circ} \mathrm{C}$ and cooling to room temperature. Photomicrographs by Yang Hu.
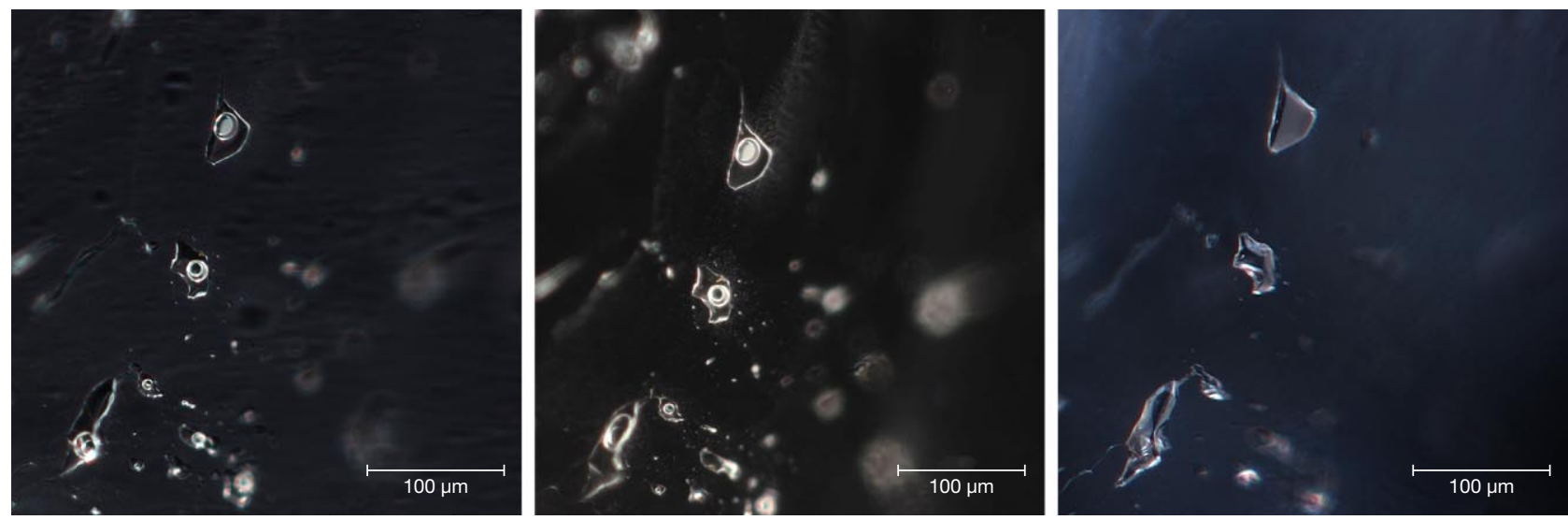

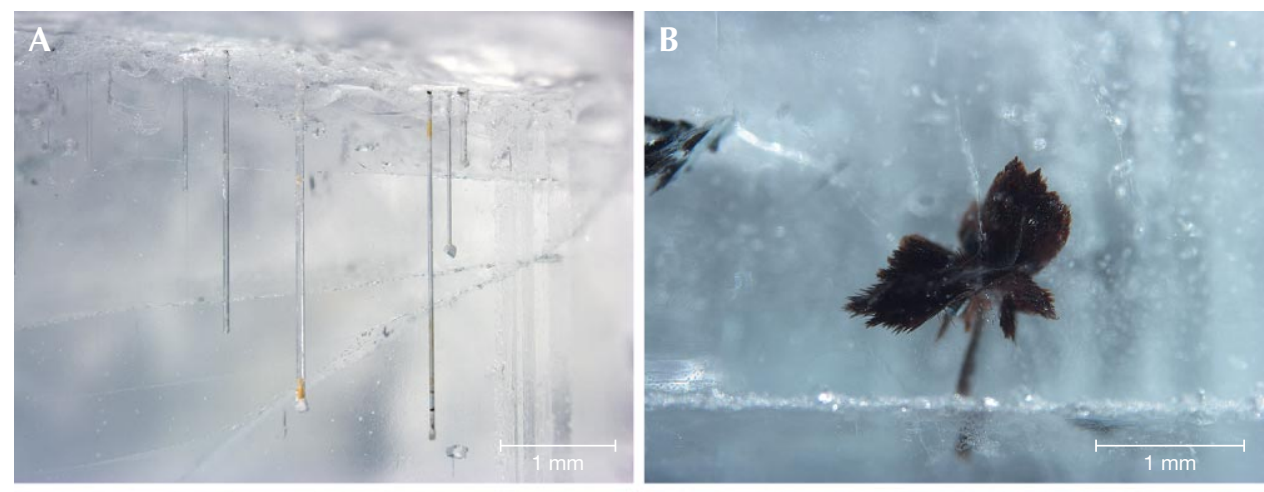

Figure 5. Various mineral inclusions in the beryl samples. A: Yellow argentojarosite inside needle-like growth tubes along the c-axis of a Pakistani aquamarine. White albite was present at the end of growth tubes. B: Brown butterfly-like tantalitecolumbite in a Pak-
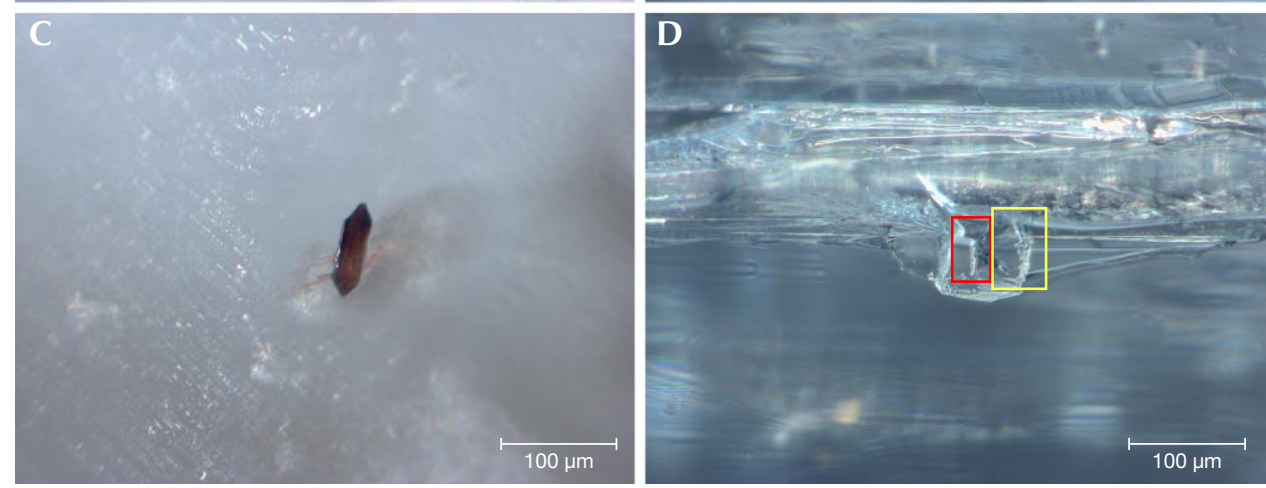
istani aquamarine. $C$ : Hexagonal brownish tantalite-columbite in a Brazilian aquamarine. $D$ : Bertrandite (red rectangle) and siderite (yellow rectangle) inclusions in an aquamarine from Mozambique. Photomicrographs by Yang $\mathrm{Hu}$.

fied only in Pakistani aquamarine, while bertrandite and siderite were recognized only in an aquamarine sample from Mozambique.

Trace Element Analysis. The alkali element and transition element contents (in ppmw) of all beryl samples from multiple localities are reported in table 2.

Alkali Elements. Among the alkali elements, Cs and $\mathrm{Na}$ concentrations were relatively enriched and $\mathrm{Rb}$ content was lowest in nearly all samples (table 2). In
Burmese aquamarine BM-1, K content (72-219 ppmw) was the lowest rather than $\mathrm{Rb}$ (1375-1459 ppmw). The concentration of $\mathrm{Li}$ was less than $\mathrm{Na}$ in all of the samples. Nearly all samples had total alkali content (including $\mathrm{Li}, \mathrm{Na}, \mathrm{K}, \mathrm{Rb}$, and $\mathrm{Cs}$ ) below approximately 6000 ppmw. Aquamarine MOZ-2 and goshenite PK10 had the lowest total alkali content (1250-1350 ppmw on average). The alkali content of deep blue Burmese aquamarine BM-1 and dark blue Brazilian aquamarine BRA-3 differed noticeably from those of other samples. $\mathrm{Li}, \mathrm{Rb}$, and $\mathrm{Cs}$ contents were more than

TABLE 2. LA-ICP-MS chemical composition analysis of beryl samples.

\begin{tabular}{lccccccccc}
\hline $\begin{array}{l}\text { Trace } \\
\text { elements } \\
(\text { ppmw) }\end{array}$ & $\begin{array}{c}\text { Goshenite } \\
\text { PK-7 }\end{array}$ & $\begin{array}{c}\text { Goshenite } \\
\text { PK-5 }\end{array}$ & $\begin{array}{c}\text { Goshenite } \\
\text { PK-10 }\end{array}$ & $\begin{array}{c}\text { Aquamarine } \\
\text { PK-8 }\end{array}$ & $\begin{array}{c}\text { Aquamarine } \\
\text { PK-9 }\end{array}$ & $\begin{array}{c}\text { Aquamarine } \\
\text { BRA-3 }\end{array}$ & $\begin{array}{c}\text { Aquamarine } \\
\text { RUS-8 }\end{array}$ & $\begin{array}{c}\text { Aquamarine } \\
\text { MOZ-2 }\end{array}$ & $\begin{array}{c}\text { Aquamarine } \\
\text { BM-1 }\end{array}$ \\
\hline $\mathrm{Li}$ & $290-357$ & $1168-1239$ & $68-75$ & $292-328$ & $73-76$ & $5633-5745$ & $270-272$ & $136-145$ & $6244-6497$ \\
$\mathrm{Na}$ & $1103-1295$ & $3845-3970$ & $827-843$ & $1099-1147$ & $1860-2039$ & $8988-9073$ & $1295-1425$ & $1031-1098$ & $7857-8102$ \\
$\mathrm{~K}$ & $94-114$ & $118-137$ & $54-69$ & $83-86$ & $434-452$ & $1036-1067$ & $16-21$ & $37-44$ & $72-219$ \\
$\mathrm{~V}$ & $1-5$ & $1-2$ & 0 & $4-5$ & $30-33$ & $17-18$ & 0 & $4-5$ & $82-84$ \\
$\mathrm{Cr}$ & $0-14$ & $0-1$ & $0-3$ & $0-4$ & $1-6$ & $3-5$ & 0 & $0-1$ & 0 \\
$\mathrm{Mn}$ & $28-30$ & $52-56$ & $17-18$ & $19-51$ & $19-23$ & $287-292$ & $23-25$ & $7-9$ & $568-854$ \\
$\mathrm{Fe}$ & $1745-1826$ & $1459-1500$ & $1355-1414$ & $1802-1950$ & $4498-5080$ & $9306-9407$ & $5466-5703$ & $5542-5554$ & $6709-7668$ \\
$\mathrm{Rb}$ & $37-42$ & $42-44$ & $9-10$ & $34-37$ & $52-63$ & $662-671$ & $7-9$ & $10-11$ & $1375-1459$ \\
$\mathrm{Cs}$ & $2261-2861$ & $622-676$ & $313-333$ & $2229-3216$ & $1366-1414$ & $17789-18005$ & $184-186$ & $133-135$ & $46510-47496$ \\
\hline
\end{tabular}

Data analyzed by LA-ICP-MS from three spots per sample. Data reported in minimum and maximum values. Detection limits $(p p m w): L i=0.36, \mathrm{Na}=7.43$, 


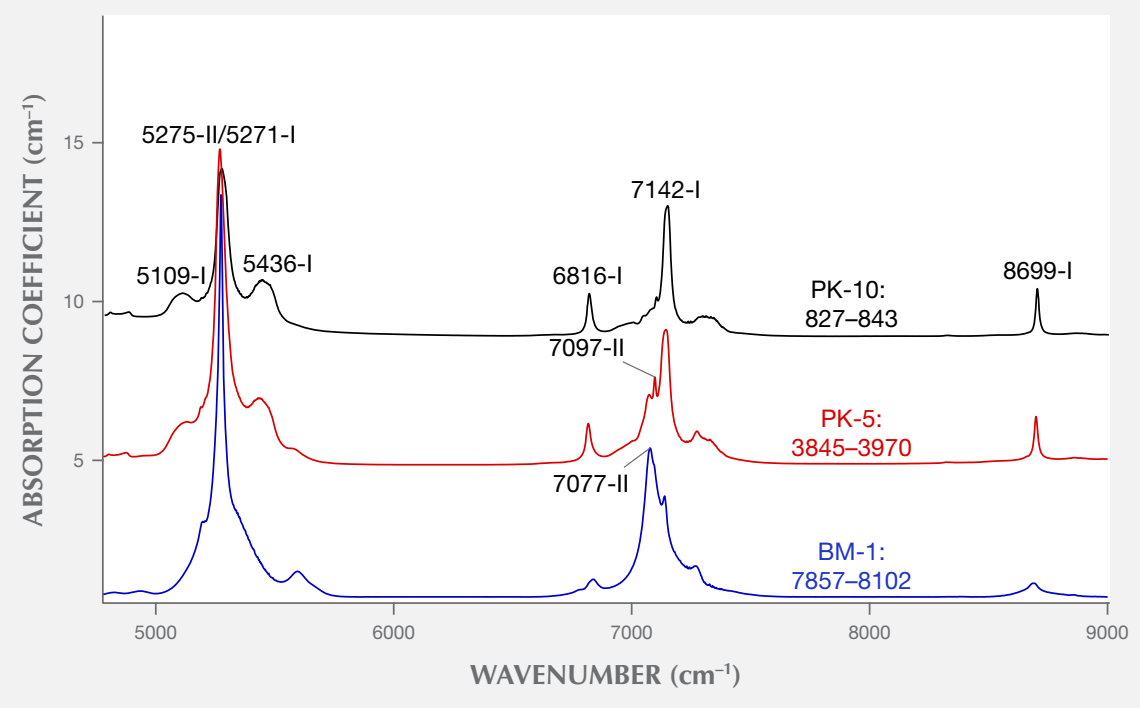

Figure 6. FT-NIR spectra of beryl wafers parallel to the c-axis. The peak intensity of type II water at 7097, 7077, and $5275 \mathrm{~cm}^{-1}$ became stronger (from top to bottom) with increasing sodium content. The spectra are displaced vertically by $y+4.5 \mathrm{~cm}^{-1}(P K-5)$ and $y+9 \mathrm{~cm}^{-1}(P K-10)$ for clarity. Note: Na content analyzed by LAICP-MS is listed in ppmw.

10 times higher, and $\mathrm{Na}$ and $\mathrm{K}$ were $3-10$ times higher (table 2). BM-1 had the richest Cs content (46510$47496 \mathrm{ppmw}$ ) reported for blue aquamarine.

Transition Metals. Concentration of Fe varied from 1355 to 9407 ppmw for all colorless and blue to yellow beryl samples (table 2). Among the samples, the colorless and near-colorless beryl (PK-10, PK-7, PK8, and PK-5) had relatively low Fe (1355-1950 ppmw). Other saturated bluish beryl contained higher Fe content, even up to 9407 ppmw. The lemon yellow and golden-colored heliodor (UK-10 and UK-11) had Fe content between 2030 and 3812 ppmw, lower than bluish beryl samples of similar saturation.

\begin{tabular}{ccccc}
\hline $\begin{array}{c}\text { Green beryl } \\
\text { MOZ-1 }\end{array}$ & $\begin{array}{c}\text { Green beryl } \\
\text { AF-3 }\end{array}$ & $\begin{array}{c}\text { Heliodor } \\
\text { AF-2 }\end{array}$ & $\begin{array}{c}\text { Heliodor } \\
\text { UK-11 }\end{array}$ & $\begin{array}{c}\text { Heliodor } \\
\text { UK-10 }\end{array}$ \\
\hline Mozambique & Africa & Africa & Unknown & Unknown \\
\hline $70-76$ & $143-149$ & $134-140$ & $162-174$ & $135-162$ \\
$508-627$ & $2507-2611$ & $1625-1797$ & $804-855$ & $1204-1443$ \\
$2-36$ & $292-297$ & $162-195$ & $51-66$ & $153-175$ \\
$257-268$ & $9-10$ & $7-14$ & 0 & 0 \\
$267-292$ & 0 & $0-2$ & $0-4$ & $2-4$ \\
$4-7$ & $95-96$ & $116-160$ & $36-43$ & $49-57$ \\
$2698-2841$ & $6899-7055$ & $6292-8217$ & $2030-2203$ & $3225-3812$ \\
$11-14$ & $169-175$ & $124-145$ & $39-46$ & $34-61$ \\
$300-370$ & $1606-1630$ & $1791-2305$ & $1952-2092$ & $510-689$ \\
\hline$=11.22, V=0.07, C r=0.88, M n=0.46, F e=12.65, R b=1.66, C s=8.22$
\end{tabular}


between 380 and $780 \mathrm{~nm}$ using GRAMS software, when the sample thickness was normalized to $4 \mathrm{~mm}$. In order to discuss the impact of Fe on coloration, we converted ppmw to ppma in the UV-Vis-NIR region by the following formulation: ppma $=[$ atomic weight of beryl/number of atoms for beryl)/atomic weight of $\mathrm{Fe}] \cdot \mathrm{ppmw}$ value $=[(537.49 / 29) / 55.85] \cdot \mathrm{ppmw}$ value. That is, ppma value $=0.3318 \mathrm{ppmw}$ value .

All blue to yellow beryl samples showed the typical iron absorption in their UV-Vis-NIR spectra. Peaks at 372 and $427 \mathrm{~nm}$ related to $\mathrm{Fe}^{3+}$ ions (Wood and Nassau, 1968) were observed in all samples (figures 7-9). These 372 and $427 \mathrm{~nm}$ peaks were more or less covered by the absorption edge in the violet-blue region in the yellowish beryl samples. They were even invisible in lemon yellow and golden heliodor (UK-10 and UK-11) (figure 7). These 372 and $427 \mathrm{~nm}$ peaks did not contribute to color because of their rather weak absorption.

The absorption edge in the violet-blue region leads to yellowish color in beryl. There was no obvious difference between the o-ray and the e-ray. This absorption edge was assigned to $\mathrm{Fe}^{3+}$ ions (Wood and Nassau, 1968). The absorption edge was present in all beryl samples, and it was in the ultraviolet region for beryl samples without yellowish color. When this absorption edge shifted to a longer wavelength from the violet-blue to the blue region, the yellow color occurred in beryl. Also, the intensity of this absorption edge was not proportional to total Fe content. For example, greenish yel-



Figure 7. Unoriented UV-Vis-NIR spectra of greenish yellow (AF-2), lemon yellow (UK-11), and golden (UK-10) heliodor samples. When the absorption edge shifted to a longer wavelength from the violetblue to the blue region, the color turned more yellowish. The spectra are displaced vertically by $\mathrm{y}+2$ $\mathrm{cm}^{-1}(U K-11)$ and $\mathrm{y}+4 \mathrm{~cm}^{-1}(\mathrm{UK}-10)$ for clarity. Note: Fe content analyzed by LA-ICP-MS is listed in ppma.

low beryl AF-2 had the richest total Fe content (20882727 ppma) of the three yellowish samples, but the intensity of the absorption edge was weak compared with other yellow heliodor samples (see figure 7).

Bluish color in the beryl samples resulted from a distinct broad absorption around $600 \mathrm{~nm}$ in the e-ray. The $600 \mathrm{~nm}$ broad absorption band was present in the e-ray but quite weak in the o-ray (see figures 8

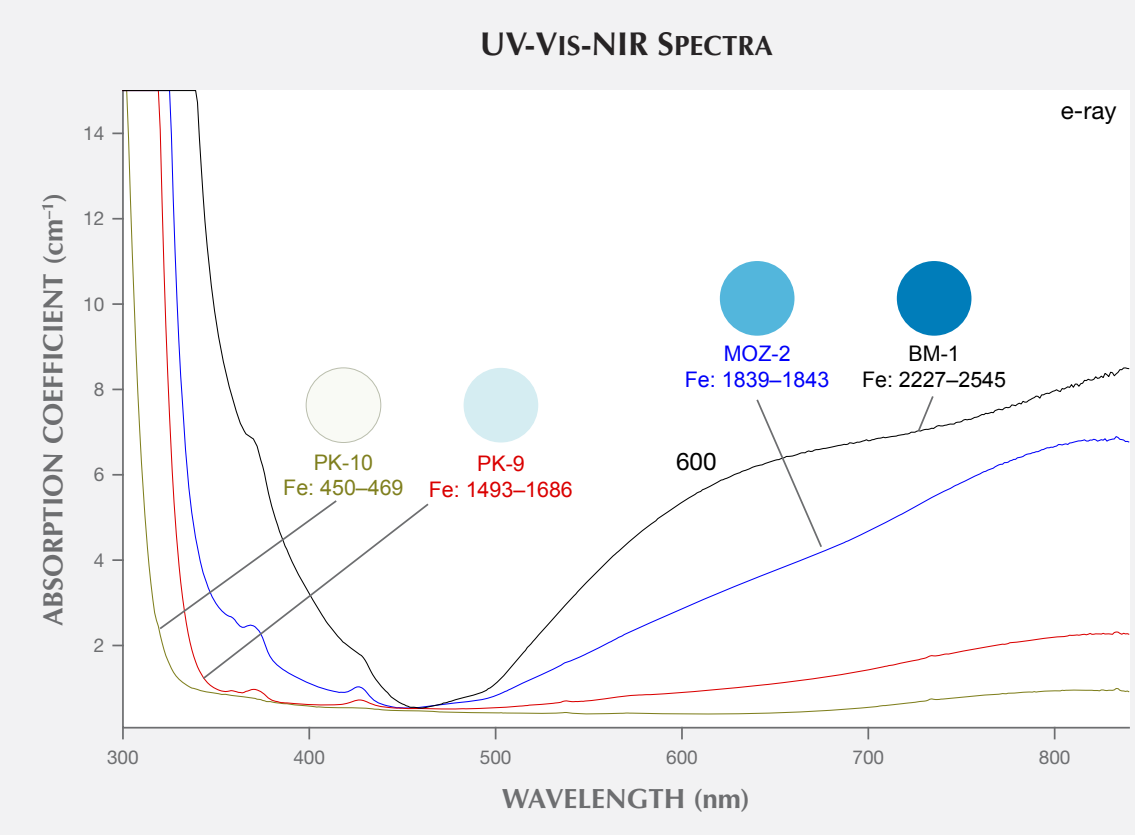

Figure 8. UV-Vis-NIR spectra of aquamarine and goshenite samples with distinguishing $\mathrm{Fe}$ content in e-ray. With increasing Fe content, the absorption band at $600 \mathrm{~nm}$ became stronger and the blue color became saturated (from bottom to top). Note: Fe content analyzed by LA-ICP-MS is listed in ppma. 


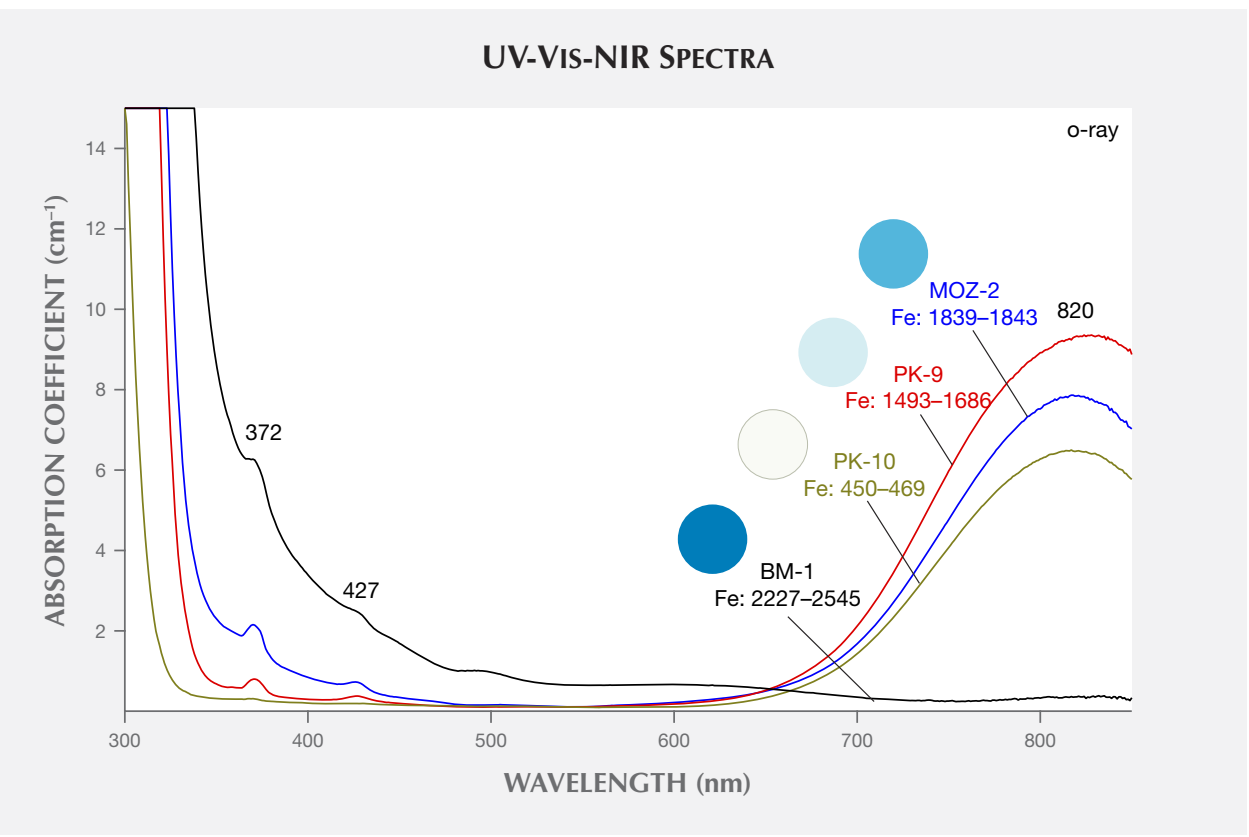

Figure 9. UV-Vis-NIR

spectra of aquamarine and goshenite samples with distinguishing $\mathrm{Fe}$ content along the o-ray. The band intensity at $820 \mathrm{~nm}$ was not proportionate to the Fe content. Note: Fe content analyzed by LA-ICP-MS is listed in ppma.

and 9), which was responsible for more blue color along the e-ray than the o-ray. This absorption was associated with $\mathrm{Fe}^{2+}$ or $\mathrm{Fe}^{2+}-\mathrm{Fe}^{3+}$ ion pairs (Wood and Nassau, 1968; Lin et al., 2013). With increasing Fe content, the $600 \mathrm{~nm}$ absorption band became stronger and the color became more saturated, from colorless, pale greenish blue, and medium blue to dark blue (from bottom to top in figure 8). Compared with Fe content in yellow heliodor with similar saturation, Fe ions were less efficient for coloring beryl blue than yellow: 600 ppma Fe in beryl could produce a relatively saturated yellow color. However, blue

Figure 10. The UV-Vis-NIR spectra of green beryl MOZ-1 showed typical absorption of $\mathrm{Cr}^{3+}$ and minor $V^{3+}$ ions, as well as Fe ions at 372 and $820 \mathrm{~nm}$.

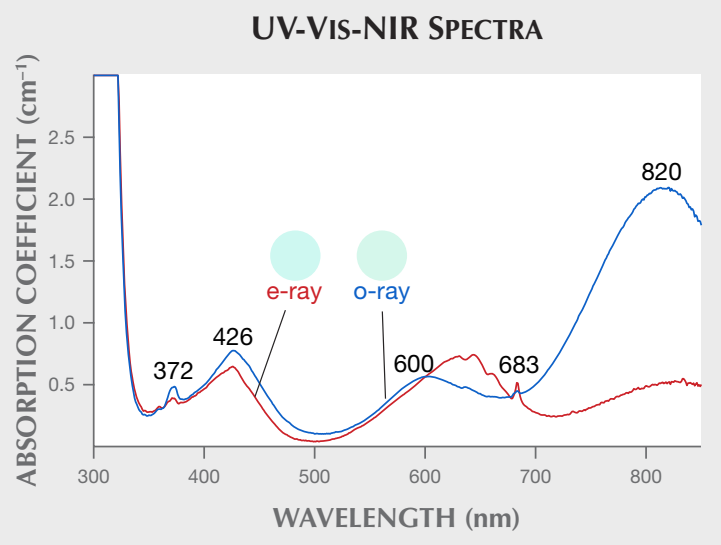

aquamarine with similar saturation should contain at least twice the Fe content.

A broad absorption band centered at about $820 \mathrm{~nm}$ was stronger in the o-ray than the e-ray /see figures 8 and 9). This $820 \mathrm{~nm}$ broad band overlapped with the $600 \mathrm{~nm}$ band in the e-ray. This band in the o-ray was related to $\mathrm{Fe}^{2+}$ (Wood and Nassau, 1968), and its intensity had nothing to do with total Fe content. For example, the $820 \mathrm{~nm}$ band intensity of Burmese aquamarine BM-1 was quite weak, contrary to the abundant Fe content (see figure 9). However, the intensity of the $820 \mathrm{~nm}$ band in the e-ray was not in proportional to that in the o-ray. And the intensity of the $820 \mathrm{~nm}$ band in the e-ray was nearly positive to the total Fe content (see figure 8). So we supposed that the origin of the $820 \mathrm{~nm}$ band was different between the e-ray and o-ray, maybe $\mathrm{Fe}^{2+}$ in different occupancy.

The tail of the $820 \mathrm{~nm}$ band reached the visible range, but its intensity in the visible range was quite weak. So this $820 \mathrm{~nm}$ broad absorption could not lead to any obvious color.

Pale green beryl MOZ-1 showed typical absorption of $\mathrm{Cr}^{3+}$ at 426 and $600 \mathrm{~nm}$ for the o-ray and 630 and $660 \mathrm{~nm}$ for the e-ray, as well as sharp R lines at $683 \mathrm{~nm}$ (Wood and Nassau, 1968). A weak V $\mathrm{V}^{3+}$ absorption shoulder was also observed at about $400 \mathrm{~nm}$ /see figure 10). So this green color originated from $\mathrm{Cr}^{3+}$ and minor $\mathrm{V}^{3+}$ ions in beryl, similar to emerald. This absorption was totally different from yellowish green beryl AF-3 (no absorption spectra shown for this sample), which showed the absorption features of Fe ions, though they both had greenish color. 

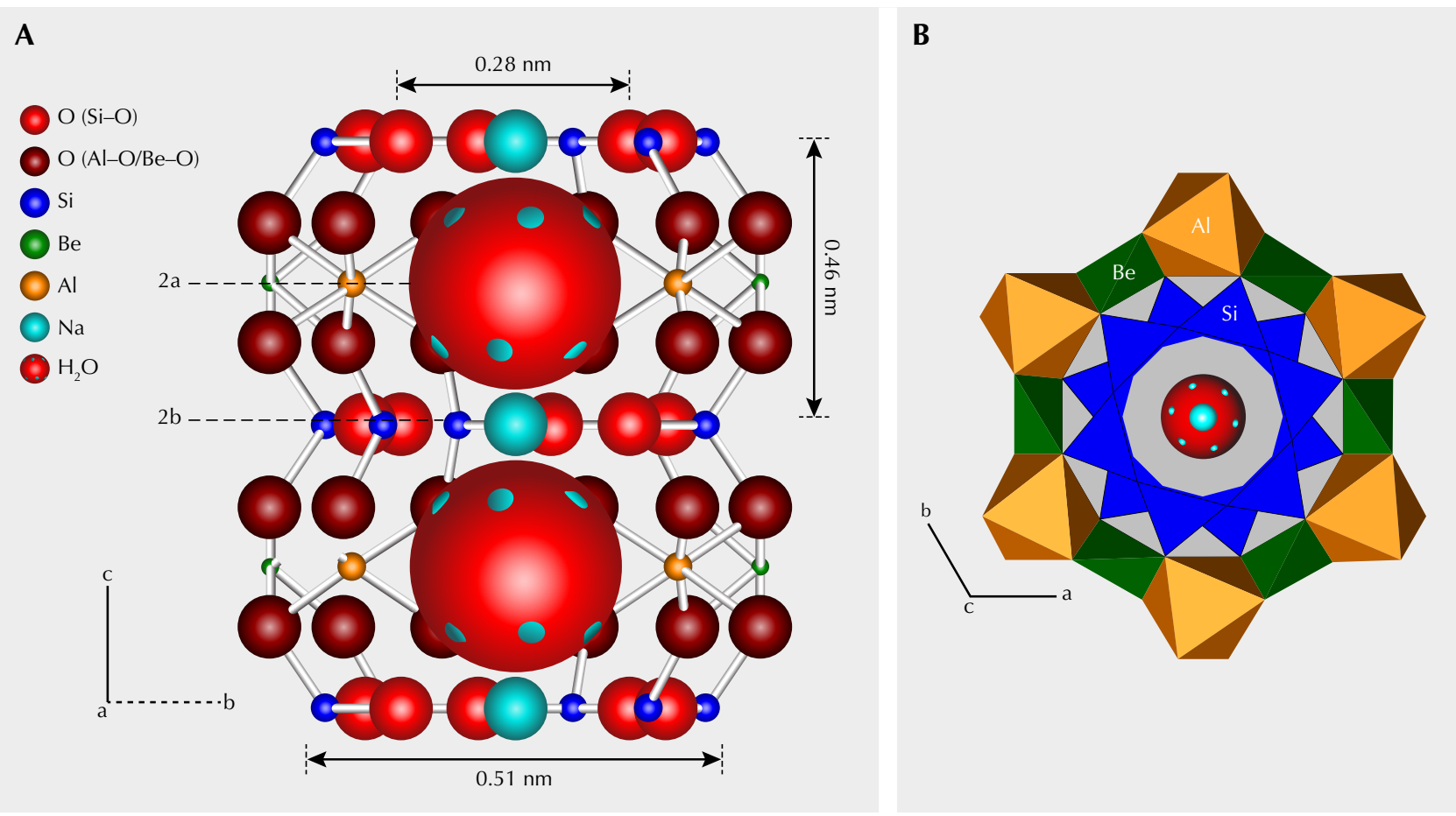

Figure 11. Diagrams of the unique peanut-shaped channel structure in beryl, and the internal arrangement of alkali ions and water, viewed as "ball-wire" down into the a-axis (with a $120^{\circ}$ angle from the b-axis, which is projected onto the page from behind as a dashed line) (A) and as "polyhedra" down into the c-axis (B). Smaller rings of $\mathrm{SiO}_{4}$ tetrahedra stack over larger rings of alternating $\mathrm{BeO}_{4}$ tetrahedra and $\mathrm{AlO}_{6}$ octahedra forming peanut-shaped enclosures. Large alkali ion $\mathrm{Cs}^{+}$or water would only be localized at the larger $2 a$ site and unable to migrate along the channel. The smallest ion $\mathrm{Na}^{+}$fits suitably at the $2 \mathrm{~b}$ site, interacting with "type II" water. The hydrogen-hydrogen direction is parallel to the c-axis in "type I" water and perpendicular to the c-axis in "type II" water. Selected atoms in figure A were omitted to better show internal details. Relevant parameters are from Artioli et al. (1993) and Wood and Nassau (1968).

\section{DISCUSSION}

Crystal Structural Consideration. The crystal structure of beryl, with an ideal chemical formula $\mathrm{Be}_{3} \mathrm{Al}_{2}\left(\mathrm{Si}_{6} \mathrm{O}_{18}\right)$, consists of smaller rings of six $\mathrm{SiO}_{4}$ tetrahedra and larger rings of alternating $\mathrm{BeO}_{4}$ tetrahedra and $\mathrm{AlO}_{6}$ octahedra (figure 11B). These two rings stack over each other along the c-axis, forming a peanut-shaped structural "channel" along the c-axis (figure 11A). Large ions such as Cs or water molecules would only fit within the large ring and be therefore localized at the 2a site and unable to migrate along the channel, because the ionic diameter of $\mathrm{Cs}^{+}(0.376 \mathrm{~nm})$ and the dimension of a water molecule $(0.28 \times 0.32 \times 0.37 \mathrm{~nm})$ are too large to fit within the $2 \mathrm{~b}$ site. Water molecules in beryl occur in two configurations: "type I" with H-H direction parallel to the c-axis, and "type $\Pi^{\prime \prime}$ with $\mathrm{H}-\mathrm{H}$ direction perpendicular to the c-axis (Wood and Nassau, 1967). Water molecules are only free to rotate around the caxis according to the hexagonal system (Gorshunov et al., 2016). Due to similar ionic radii and chemical properties, minor $\mathrm{K}^{+}$and $\mathrm{Rb}^{+}$ions in the channel behave like $\mathrm{Cs}^{+}$ions. The smallest alkali ions coordinated in the $2 \mathrm{~b}$ site, $\mathrm{Na}^{+}$, are stable because of Coulomb interactions between $\mathrm{Na}^{+}$and adjacent type II water molecules (see again figure 11A).

Substitutions commonly occur in Be-O tetrahedra by $\mathrm{Li}^{+}$ions, and in $\mathrm{Al}-\mathrm{O}$ octahedra by transition metal ions and other ions (such as $\mathrm{Mg}, \mathrm{Ca}$, and $\mathrm{Ti}$ ). With $\mathrm{Li}^{+}$ substituting for $\mathrm{Be}^{2+}$, slight deformation of Be-O tetrahedra and charge deficiency arise. Substitution of divalent cations in $\mathrm{Al}$ octahedra or trivalent cations in Be tetrahedra could also lead to charge deficiency. Alkali ions (mainly $\mathrm{Cs}^{+}$and $\mathrm{Na}^{+}$) in the channel serve to charge balance (e.g., $\mathrm{Li}^{+}+$transition metal ions + other substituted ions $=\mathrm{Cs}^{+}+\mathrm{Na}^{+}$). Moreover, the substitution of transition metal ions mainly included $\mathrm{Fe}^{2+} / \mathrm{Fe}^{3+} / \mathrm{Mn}^{2+} / \mathrm{Mn}^{3+} / \mathrm{Cr}^{3+} / \mathrm{V}^{3+}<=>\mathrm{Al}^{3+}$, or in some cases $\mathrm{Fe}^{2+} / \mathrm{Fe}^{3+}<=>\mathrm{Be}^{2+}$.

Alkali Elements. The relative concentrations of each alkali element were nearly proportional in all beryl samples, showing similar variation (figure 12). This was in agreement with the charge balance principle, in which the charge deficiency arising from the substitu- 




Figure 12. The concentration of five alkali elements for all beryl samples from different locations showed a similar proportional tendency. A log scale was used for the $y$ axis.

tion of $\mathrm{Li}$ are compensated by a proportional amount of $\mathrm{Na}$ and $\mathrm{Cs}$ plus minor $\mathrm{K}$ and $\mathrm{Rb}$ in the channel. But there were also some inconsistencies, especially the unexpectedly low $\mathrm{K}$ content in Burmese aquamarine BM-1. This proportional tendency may result from the process of crystallization in the mineralizing fluid with abundant $\mathrm{Li}, \mathrm{Na}, \mathrm{K}, \mathrm{Rb}$, and $\mathrm{Cs}$ at the same time.

The chemical fingerprint diagram of $\mathrm{Li}$ versus $\mathrm{Cs}$ content showed two concentrated areas, which could be considered the "low-alkali beryl" area (red circle in figure 13) and the "high-alkali beryl" area (blue circle in figure 13). Low-alkali beryl was dominated by type I water and high-alkali beryl by type II water analyzed by FT-NIR spectra. This was in agreement with the fact that $\mathrm{Na}^{+}$coordinates with type II water molecules in the channel (see figure 11A) and each alkali was nearly proportional. Beryl samples from most localities were in the low-alkali beryl area including Pakistan, Russia, Africa, Mozambique, Italy (Bocchio et al., 2009), Vietnam (Huong et al., 2011),

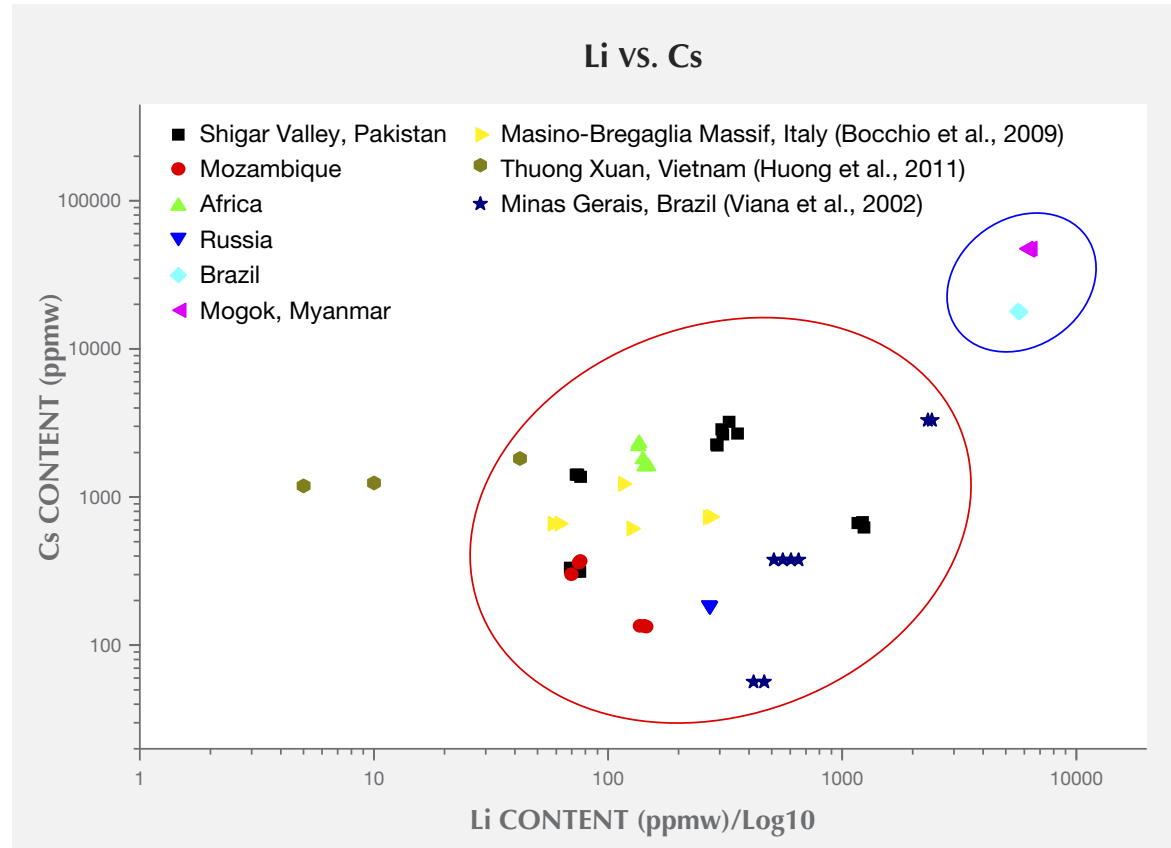

Figure 13. The chemical fingerprint diagram of the log-log plot of Li versus Cs content in beryl samples from various localities shows two concentrated areas considered the "low-alkali" (red circle) and "highalkali" (blue circle) areas. 


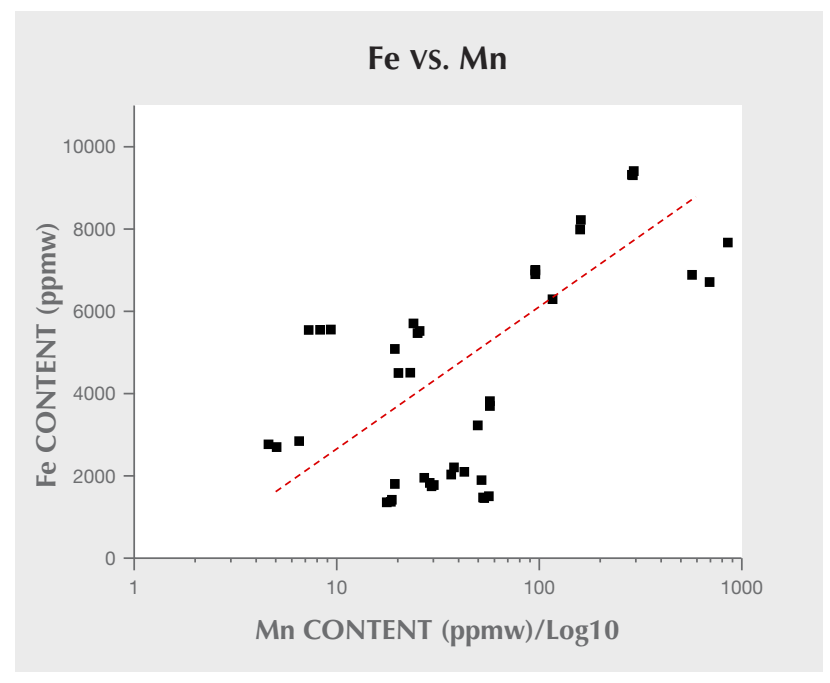

Figure 14. Fe and Mn concentrations showed an approximately positive relationship in all 14 blue to yellow samples, indicating similar substitution behavior.

and Minas Gerais, Brazil (Viana et al., 2002). Although this Li-Cs plot could not be used to distinguish the exact geographic origin, it showed the possibility of separating blue to yellow beryl from locations worldwide by various chemical fingerprint diagrams.

Chromophores Fe and Mn. Concentrations of Fe and Mn showed an approximately positive relationship in blue to yellow beryl samples, though they were not quite proportional (figure 14). This positive relationship could be explained by Fe and Mn's similar substitution behavior according to similar radii, ionic valence, and coordination. Mn and Fe ions were normally present as two possible valence states: +2 and +3 in beryl. Radii of $\mathrm{Mn}$ ions (approximate measurements of $\mathrm{Mn}^{2+}: 0.066$ $0.083 \mathrm{~nm} ; \mathrm{Mn}^{3+}: 0.058-0.064 \mathrm{~nm}$ ) are quite similar to Fe ions $\left(\mathrm{Fe}^{2+}: 0.063-0.078 \mathrm{~nm} ; \mathrm{Fe}^{3+}: 0.049-0.054 \mathrm{~nm}\right)$ (Shannon, 1976). Both ions were more likely to substitute for $\mathrm{Al}^{3+}$ in the octahedral site due to suitable radii in beryl. Moreover, Fe and Mn ions could enrich together in mineralized fluid due to similar geochemical features. Therefore, blue to yellow beryl showed similar substitution behavior during crystallization.

The Chromophore Mn and Color. Mn ions in blue to yellow beryl did not impart an obvious red modification to the hue, and no obvious pink, purple, or orange hues were seen. Red beryl and morganite are considered to be colored by $\mathrm{Mn}^{2+}$ or $\mathrm{Mn}^{3+}$ (Nassau and Wood, 1968; Platonov et al., 1989; Fridrichová et al., 2017). Red beryl generally contains 2000 ppmw Mn (Shigley et al., 1984), and morganite has less than 200 ppmw Mn (authors' unpublished data). However, our blue to yellow beryl samples with abundant Mn con- tent showed no obvious absorption of $\mathrm{Mn}$ ions in UVVis-NIR spectra and a corresponding pink, orange, or purple color. For example, the Mn content of deep blue aquamarine BM-1 (568-854 ppmw) was nearly half that of red beryl. And the Mn content in Brazilian dark greenish blue aquamarine BRA-3 (287-292 ppmw) and greenish yellow sample AF-2 (116-160 ppmw) was close to morganite. This indicated that Mn ions in blue to yellow beryl do not play a role in coloration, and the valence or occupancy of Mn ions should differ from that in morganite or red beryl. The valence or occupancy of $\mathrm{Mn}$ ions may be affected by high Fe content (the Fe/Mn ratio was at least close to an order of magnitude greater). The valence, occupation, and coloration of $\mathrm{Mn}$ ions in beryl will be discussed in detail in a future study.

Blue to Yellow Color Characteristics. We determined that Fe ions in beryl could lead to yellow and blue colors. Blue color has been attributed to $\mathrm{Fe}^{2+}$ or $\mathrm{Fe}^{2+}-\mathrm{Fe}^{3+}$ pairs, and yellow color to $\mathrm{Fe}^{3+}$ (Wood and Nassau, 1968; Lin et al., 2013), though their accurate occupancy remains controversial. Recently, an alternative mechanism involving trapped electrons in the creation and the decay of the yellow color was proposed by Andersson (2013). But the exact configurations of the electron trap and the tetrahedral $\mathrm{Fe}^{3+}$ color center could not be determined. Due to different proportions of $\mathrm{Fe}$ ions with various valences and occupancies in beryl, color varied from yellow to greenish yellow, yellowish green, bluish green, greenish blue, and blue. The greenish color was normally modified by a yellowish or bluish component, such as yellowish green sample AF-3 and bluish green sample RUS-8. Green color could also be caused by other distinct coloration mechanisms, $\mathrm{Cr}^{3+}$ and/or $\mathrm{V}^{3+}$, the same as emerald (e.g., green beryl MOZ1). But the green beryl had a lower color saturation than emerald due to inadequate $\mathrm{Cr}$ and/or V content.

Alkali and Color. The alkali ions showed no obvious impact on blue to yellow color of beryl. The alkali ions serve for charge deficiency arising from the substitution of some transition metals, but no corresponding relationship occurred between the alkali content and $\mathrm{Fe} / \mathrm{Mn}$ content for blue to yellow beryl samples. This could be because at least some Fe and Mn ions substituted without charge deficiency (i.e., $\mathrm{Fe}^{3+} / \mathrm{Mn}^{3+}<=>\mathrm{Al}^{3+}$, or $\mathrm{Fe}^{2+} / \mathrm{Mn}^{2+}<=>\mathrm{Be}^{2+}$ ), or other substituted ions (such as $\left.\mathrm{Zn}^{2+}, \mathrm{Mg}^{2+}\right)$ participated in charge balance. Alkali ions, therefore, had no direct impact on the chromophores and their coloration of blue to yellow beryl. Nevertheless, our high-alkali beryl appeared to show deeper 
blue color. The additional dark hue of BRA-3 was caused by dark cloudy inclusions. It was worth noting that bluish samples could be "low-alkali" or "high-alkali" beryl, but all yellowish samples were "low-alkali" beryl. This manifested that the alkali may influence the valence or occupancy of Fe ions, but it required further confirmation.

Water and Color. Water type and its relative content played little role in the blue to yellow color of beryl. All blue to yellow samples contained both type I and type II water in the channel. Nor was there any relationship between the type I/type II water ratio and color hue or saturation. Water molecules were related to chromophores in beryl through $\mathrm{Na}$ ions, but $\mathrm{Na}$ ions showed no obvious impact on the coloration of blue to yellow beryl. Therefore, it was unlikely that water molecules would affect beryl's blue to yellow color.

\section{CONCLUSIONS}

Blue to yellow gem beryl was studied by quantitative chemistry and spectroscopic properties to understand

ABOUT THE AUTHORS

Mr. Hu is a PhD student at the Gemological Institute, China University of Geosciences in Wuhan.Dr. Lu (renlu.cc@gmail.com) is a distinguished professor at the Gemological Institute, China University of Geosciences in Wuhan. the chromophores and color characteristics. Blue color was caused by a broad absorption band at $600 \mathrm{~nm}$, and yellow color was attributed to an absorption edge in the violet-blue region. Both were related to Fe ions in different valences and occupancies. Green beryl was colored by a combination of yellow and blue, or by $\mathrm{Cr}^{3+}$ and/or minor $\mathrm{V}^{3+}$. The concentration of $\mathrm{Mn}$ was somewhat positively related to Fe in blue to yellow beryl, but abundant $\mathrm{Mn}$ ions had no impact on color.

This study discussed the arrangement of alkali ions and water molecules within the structural channel, facilitating charge compensation among the channel species and aliovalent substitutions in the surrounding rings. Large $\mathrm{Cs}^{+}, \mathrm{Rb}^{+}, \mathrm{K}^{+}$ions and water molecules were localized at the $2 \mathrm{a}$ site and were unable to migrate along the channel. The smallest ions $\left(\mathrm{Na}^{+}\right)$stably positioned at the $2 \mathrm{~b}$ site, interacting with "type II" water. Non-nominal (not in chemical formula) alkali elements ( $\mathrm{Li}, \mathrm{Na}, \mathrm{K}, \mathrm{Rb}$, and $\mathrm{Cs}$ ) and water were relevant and played complex roles in beryl. However, we found the influence on blue to yellow color to be indirect and possibly weak.

\section{ACKNOWLEDGMENTS}

The authors would like to thank the editorial improvement on this manuscript. We also thank anonymous reviewers for their constructive comments. This study was supported by the Center for Innovative Gem Testing Technology, China University of Geosciences.

\section{REFERENCES}

Andersson L.O. (2013) The yellow color center and trapped electrons in beryl. Canadian Mineralogist, Vol. 51, No. 1, pp. 1525, http://dx.doi.org/10.3749/canmin.51.1.15

Artioli G., Rinaldi R., Stahl K., Zanazzi P.F. (1993) Structure refinements of beryl by single-crystal neutron and X-ray diffraction. American Mineralogist, Vol. 78, pp. 762-768.

Belakovskiy D., Bradshaw J., Cairncross B., Falster A.U., et al. (2005) Beryl and Its Color Varieties - Aquamarine, Heliodor, Morganite, Goshenite, Emerald, and Red Beryl, English Edition. Lapis International LLC, East Hampton, Connecticut.

Bocchio R., Adamo I., Caucia F. (2009) Aquamarine from the Masino-Bregaglia Massif, Central Alps, Italy. GÆG, Vol. 45, No. 3, pp. 204-207, http://dx.doi.org/10.5741/GEMS.45.3.204

Fridrichová J., Bacík P., Ertl A., Wildner M., Dekan J., Miglierini M. (2017) Jahn-Teller distortion of $\mathrm{Mn}^{3+}$-occupied octahedra in red beryl from Utah indicated by optical spectroscopy. Journal of Molecular Structure, Vol. 1152, pp. 79-86, https://doi.org/10.1016/ j.molstruc.2017.09.081

Gorshunov B.P., Torgashev V.I., Zhukova E.S., Thomas V.G., et al. (2016) Incipient ferroelectricity of water molecules confined to nano-channels of beryl. Nature Communications, Vol. 7, No. 1284, http://dx.doi.org/10.1038/ncomms 12842

Huong L.T.-T., Hofmeister W., Häger T., Khoi N.N., Nhung N.T., Atichat W., Pisutha-Arnond V. (2011) Aquamarine from the Thuong Xuan District, Thanh Hoa Province, Vietnam. Ge G, Vol. 47, No. 1, pp. 42-48, http://dx.doi.org/10.5741/GEMS.47.1.42
Lin J., Chen N., Huang D., Pan Y. (2013) Iron pairs in beryl: New insights from electron paramagnetic resonance, synchrotron $\mathrm{X}$ ray absorption spectroscopy, and ab initio calculations. American Mineralogist, Vol. 98, No. 10, pp. 1745-1753, http://dx.doi.org/10.2138/am.2013.4472

Liu Y.S., Hu Z.C., Gao S., Günther D., Xu J., Gao C.G., Chen H.H. (2008) In situ analysis of major and trace elements of anhydrous minerals by LA-ICP-MS without applying an internal standard. Chemical Geology, Vol. 257, No. 1-2, pp. 34-43, http://dx.doi.org/ 10.1016/j.chemgeo.2008.08.004

Nassau K., Wood D.L. (1968) An examination of red beryl from Utah. American Mineralogist, Vol. 53, No. 5/6, pp. 801-806.

Platonov A.N., Taran M.N., Klyakhin V.A. (1989) On two colour types of $\mathrm{Mn}^{3+}$-bearing beryls. Zeitschrift der Deutschen Gemmologischen Gesellschaft, Vol. 38, pp. 147-154.

Viana R.R., Jordt-Evangelista H., Costa G.M., Stern W.B. (2002) Characterization of beryl (aquamarine variety) from pegmatites of Minas Gerais, Brazil. Physics and Chemistry of Minerals, Vol. 29, No. 10, pp. 668-679, http://dx.doi.org/10.1007/s00269002-0278-y

Wood D.L., Nassau K. (1967) Infrared spectra of foreign molecules in beryl. Journal of Chemical Physics, Vol. 47, No. 7, pp. 22202228, http://dx.doi.org/10.1063/1.1703295

(1968) The characterization of beryl and emerald by visible and infrared absorption spectroscopy. American Mineralogist, Vol. 53, No. 5, pp. 777-800. 